\title{
THE ROLE OF TOLVAPTAN IN
}

\section{SYNDROME OF INAPPROPRIATE ANTIDIURETIC HORMONE SECRETION: clinical outcomes and effect on length of stay}

López Vázquez Y, Páramo Fernández C, Barragáns Pérez M, Trigo Barros C, Martínez González Á, Lago Garma J

Complejo Hospitalario Universitario de Vigo (Spain).

\section{OBJECTIVES}

Hyponatremia is the most common electrolyte imbalance among hospitalized patients. Syndrome of inappropriate antidiuretic hormone secretion (SIADH) is considered the most frequent etiology on patients with euvolemic hyponatremia. Conventional treatment includes water restriction and salt tablets with limited efficacy and very slow onset of action in certain patients ${ }^{1,2}$.
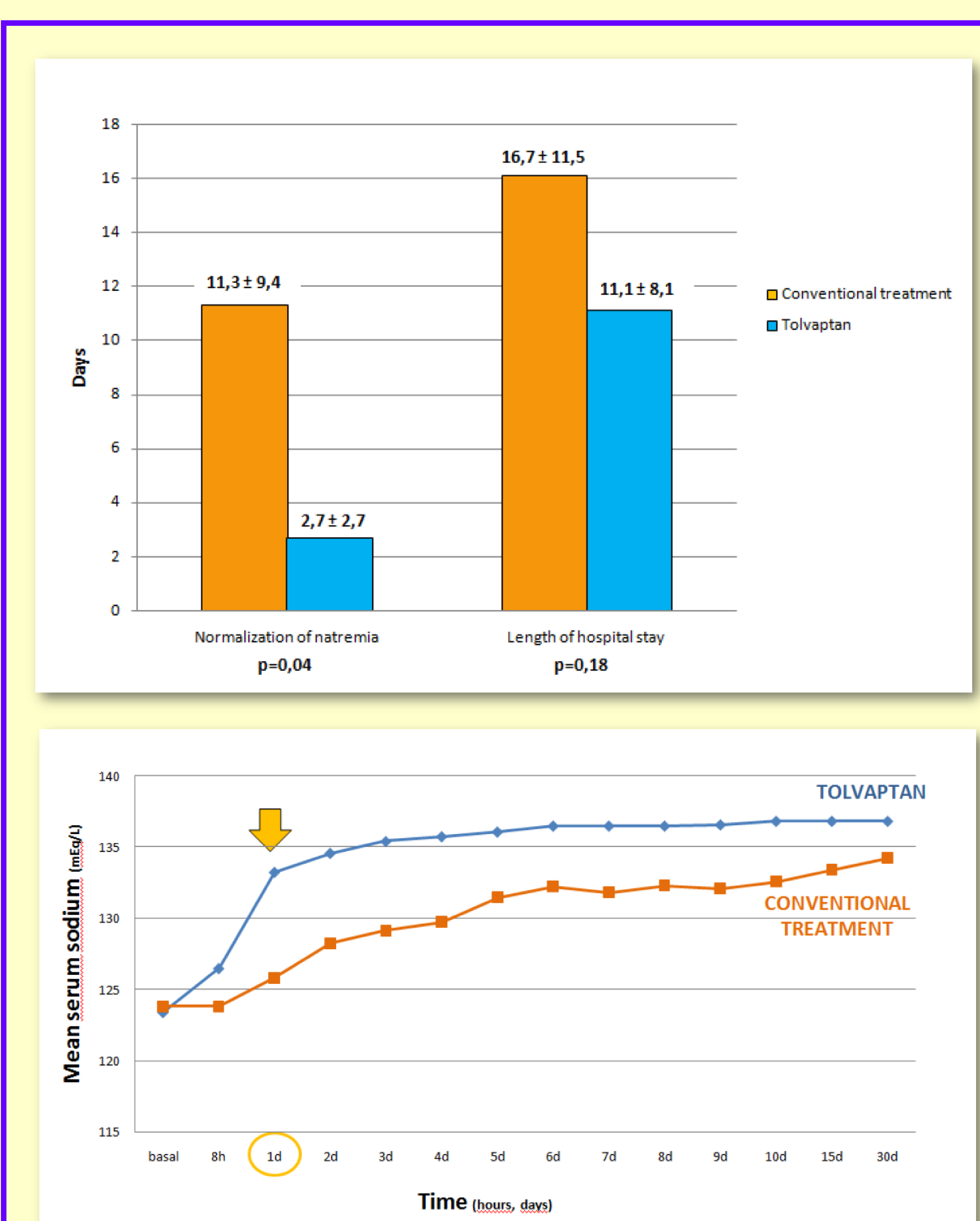

\section{CONCLUSIONS}

Tolvaptan treatment in SIADH patients shows a rapid normalization of natremia, effectively reducing inpatient length of stay.

\section{METHODS}

Systematic sampling of all SIADH patients treated with tolvaptan (group $A, n=12$ ) in our service over the last two years was compared to 12 within the conservative treatment group (group B). The average age was similar in both groups ( $A$ : 71.8 years vs $B: 71.6$ years) with a clear male predominance in the whole sample. The average plasma sodium was also similar (A: 123.4 $\mathrm{mmol} / \mathrm{L}$ vs B: $123.8 \mathrm{mmol} / \mathrm{L})$. SIADH etiology was mainly neurosurgical (A: 9 patients and $B: 7$ patients) The length of hospital stays was compared with the time span till natremia normalization in both groups. The variables are expressed as mean \pm standard deviation. The statistical analysis used was t-Student. P-value < 0.05 was considered significant.

\section{RESULTS}

The length of hospital stay from the beginning of the treatment was $11.1 \pm 8.1$ days in the tolvaptan-treated group and $16.7 \pm 11.5$ days in the conservativetreatment group $(p=0.18)$. The mean hospital stay was higher for those treated with conservative therapy. Normalization of natremia took $2.7 \pm 2.7$ days in the tolvaptan-treated group and $11.3 \pm 9.4$ days in the conservative-treatment group. The speed of correction of the hyponatremia was statistically significant for those in the tolvaptan-treated group $(p=0.04)$.

\section{References}

Verbalis JG, Adler S, Schrier RW, Berl T, Zhao Q, Czerwiec FS. Efficacy and safety of oral tolvaptan therapy in patients with the syndrome of inappropriate antidiuretic hormone secretion. Eur J Endocrinol. 2011 May;164(5):725-32

2. Peri A. Clinical review: the use of vaptans in clinical endocrinology. J Clin Endocrinol Metab. 2013 Apr;98(4):1321-32. 